\title{
Importance of anterior leaflet tethering in predicting recurrence of ischemic mitral regurgitation after restrictive annuloplasty
}

\author{
Leen van Garsse, MD, ${ }^{a}$ Sandro Gelsomino, $\mathrm{MD}, \mathrm{PhD},{ }^{\mathrm{a}, \mathrm{b}}$ Fabiana Lucà, $\mathrm{MD},{ }^{\mathrm{b}}$ Roberto Lorusso, $\mathrm{MD}, \mathrm{PhD},{ }^{\mathrm{c}}$ \\ Carmelo Massimiliano Rao, MD, ${ }^{\mathrm{b}}$ Pieluigi Stefàno, $\mathrm{MD},{ }^{\mathrm{b}}$ and Jos Maessen, $\mathrm{MD}, \mathrm{PhD}^{\mathrm{a}}$
}

\begin{abstract}
Objective: We investigated the relationship between anterior mitral leaflet (AML) tethering and recurrent ischemic mitral regurgitation (MR) after restrictive annuloplasty. We also explored whether the effect of AML tethering was secondary to modifications in left ventricular size and geometry.
\end{abstract}

\begin{abstract}
Methods: The study population consisted of 435 consecutive patients with chronic ischemic MR who survived combined coronary artery bypass grafting and undersized mitral ring annuloplasty performed at 3 institutions (University Hospital, Maastricht, The Netherlands; Careggi Hospital, Florence, Italy; and Civic Hospital, Brescia, Italy) from 2001 to 2008. The median follow-up was 44.7 months (interquartile range 25.9-66.4). The patients were divided by the baseline measurements into quintiles of AML tethering angle $\alpha^{\prime}$ as follows: group 1, normal/slight AML tethering; group 2, mild AML tethering; group 3, moderate AML tethering; group 4, moderate-to-severe AML tethering; and group 5, severe AML tethering.
\end{abstract}

Results: Recurrence of MR was significantly greater in patients with moderate-to-severe $(28.3 \%)$ and severe (39.4\%) AML tethering $(P<.001)$. A strong correlation was found between $\alpha^{\prime}(r=0.83, P<.001)$ and recurrent MR but a weak correlation with the posterior mitral angle $\beta^{\prime}(r=0.12, P=.05)$. On logistic regression analysis corrected for other echocardiographic risk factors, moderate-severe AML tethering or worse (adjusted odds ratio, 3.6; 95\% confidence interval, 3.0-4.1; $P<.001$ ) was a strong predictor of MR recurrence. Compared with patients with $\beta^{\prime}$ of 45 or greater, those with severe and moderate-severe AML tethering had more than 3.7 and 1.7 times greater odds of MR recurrence, respectively. No significant interactions were found between $\alpha^{\prime}$ and the indexes of left ventricular function and geometry.

Conclusions: Preoperative moderate-severe AML tethering or worse was strongly associated with MR recurrence. Thus, assessment of leaflet tethering should be incorporated into clinical risk assessment and prediction models. (J Thorac Cardiovasc Surg 2012;143:S54-9)

Despite undersized mitral ring annuloplasty (UMRA) being considered effective for chronic ischemic mitral regurgitation (MR), ${ }^{1}$ ongoing dissatisfaction with MR recurrence has been reported predominantly related to continued adverse left ventricular (LV) remodeling and ensuing worsening of leaflet tethering. ${ }^{2}$

More recently, attention has been drawn to the preoperative tethering pattern to predict MR recurrence. Nonetheless, the published data are conflicting, ${ }^{3-5}$ and it is still unclear whether a specific preoperative leaflet configuration is related to the unfavorable outcomes.

From the Department of Cardiothoracic Surgery, ${ }^{\mathrm{a}}$ University Hospital, Maastricht, The Netherlands; Department of Heart and Vessels, ${ }^{\mathrm{b}}$ Careggi Hospital, Florence, Italy; and Cardiac Surgery, ${ }^{\mathrm{c}}$ Civic Hospital, Brescia, Italy.

Disclosures: Leen van Garsse, Sandro Gelsomino, Fabiana Lucà, Roberto Lorusso, Carmelo Massimiliano Rao, Pieluigi Stefàno, Jos Maessen have nothing to disclose with regard to commercial support.

Leen van Garsse and Sandro Gelsomino contributed equally to this article.

Presented at The American Association for Thoracic Surgery Mitral Conclave, New York, New York, May 5-6, 2011.

Received for publication May 11, 2011; revisions received Sept 15, 2011; accepted for publication Sept 28, 2011; available ahead of print Nov 4, 2011.

Address for reprints: Sandro Gelsomino, MD, PhD, Experimental Surgery Unit, Careggi Hospital, Viale Morgagni 85, Florence 50134 Italy (E-mail: sandro. gelsomino@libero.it).

$0022-5223 / \$ 36.00$

Copyright (c) 2012 by The American Association for Thoracic Surgery doi:10.1016/j.jtcvs.2011.09.061
In the present multicenter study, we investigated the relationship between anterior mitral leaflet (AML) tethering characteristics and postoperative MR recurrence.

\section{MATERIALS AND METHODS}

Ethical committee approval was waived owing to the retrospective analysis of the study according to national laws regulating observational retrospective studies (Italian law no. 11960, released on July 13, 2004; Dutch WMO law). However, all patients gave their informed consent to access their data for scientific purposes.

The study population consisted of 435 consecutive patients with chronic ischemic MR who survived combined coronary artery bypass grafting and UMRA performed at 3 institutions (University Hospital, Maastricht, The Netherlands; Careggi Hospital, Florence, Italy; and Civic Hospital, Brescia, Italy) from 2001 to 2008 . The definition and inclusion and exclusion criteria were as previously reported. ${ }^{5}$ The median follow-up was 44.7 months (interquartile range, 25.9-66.4).

All patients underwent complete revascularization. The ring size was determined by standard measurements of the intertrigonal distance and anterior leaflet height. Downsizing by 2 ring sizes was performed in all patients. A successful repair was assessed as leaflet coaptation of $0.8 \mathrm{~cm}$ or more, MR of 1 or less, and a systolic MV area exceeding $2 \mathrm{~cm}^{2}$ at intraoperative transesophageal echocardiography.

\section{Echocardiographic Studies}

Examinations were performed using a commercially available echocardiographic system (IE 33; Philips Medical System, Amsterdam, The Netherlands). Transthoracic echocardiography was performed 


\section{Abbreviations and Acronyms \\ $\mathrm{AML}=$ anterior mitral leaflet \\ $\mathrm{LV}=$ left ventricular \\ $\mathrm{MR}=$ mitral regurgitation \\ $\mathrm{PML}=$ posterior mitral leaflet \\ UMRA $=$ undersized mitral ring annuloplasty}

before surgery and was repeated annually. All examinations were performed by experienced echocardiographers and stored on a magnetooptical disc. Standard measurements and calculations, quantification of MR, and papillary muscle displacement were performed, as previously reported. $^{5}$

The AML tethering angle $\alpha^{\prime}$ and the posterior mitral leaflet (PML) angle $\beta^{\prime}$ were directly measured with specific software (Philips DICOM Viewer, Philips Medical System). The excursion angles $\alpha_{\text {ex }}^{\prime}$ and $\beta_{\text {ex }}^{\prime}$ were calculated as the difference between the AML and PML angles in systole and diastole. The anterior/posterior tethering angle ratio $\alpha^{\prime} / \beta^{\prime}$ was a quantitative measurement of tethering. The more this ratio approached 1 , the more symmetric was the tethering. Measurements were made off line by 2 cardiologists (F.L. and C.M.R.), who were unaware of the aim of the present study. The Cohen method ${ }^{6}$ showed excellent agreement between the intraobserver and interobserver measurements with a concordance of $0.97,0.98$, and 0.96 for $\alpha^{\prime}, 0.94,0.95$, and 0.92 for $\beta^{\prime}$ and $0.95,0.98$, and 0.94 for coaptation height measured in 20 randomly selected patients for intraobserver 1, intraobserver 2, and interobserver values, respectively. The primary endpoint was the recurrence of MR at the latest echocardiographic follow-up visit. This was defined as insufficiency of $2+$ or more in patients with no/trivial MR at discharge.

\section{Patient Classification}

The patients were divided by baseline measurements into quintiles of the AML tethering angle $\alpha^{\prime}$ as follows: group 1, normal/slight AML tethering, $\alpha^{\prime}$ less than $29.8^{\circ}$; group 2, mild AML tethering, $\alpha^{\prime}$ of $29.8^{\circ}$ or greater but less than $33.4^{\circ}$; group 3, moderate AML tethering, $\alpha^{\prime}$ of $33.4^{\circ}$ or greater but less than $36.9^{\circ}$; group 4 , moderate-severe AML tethering, $\alpha^{\prime}$ of $36.9^{\circ}$ or less but less than $40.1^{\circ}$; and group 5, severe AML tethering, $\alpha^{\prime}$ greater than $40.1^{\circ}$.

The patient characteristics are summarized in Table 1. No difference was found in the baseline demographics and operative variables among the groups. In contrast, significant differences were found in the echocardiographic parameters. The subjects with AML tethering that was moderate-severe or greater had preoperatively larger and more spherical $\mathrm{LV}$ ventricles and worse LV function (all, $P<.001$ ). Furthermore, these patients showed more symmetric tethering $(P=.001)$, a lower AML excursion angle $(P=.03)$, a more accentuated anterior papillary muscle displacement either in the lateral $(P=.004)$ or posterior $(P<.001)$ direction, a larger papillary muscle separation $(P=.01)$, and a more accentuated anterolateral papillary muscle wall motion score index $(P<.001)$.

\section{Statistical Analysis}

Continuous data are expressed as the mean \pm standard deviation, nonnormal data are presented as the median and interquartile range, and categorical variables as frequencies. The variables were compared across $\alpha^{\prime}$ categories with analysis of variance, Kruskal-Wallis, and $\chi^{2}$ tests with Tukey's and Dunn's post hoc tests, as appropriate.

Pearson's correlation analysis was used to test for univariate linear relationships between indexes of tethering and postoperative MR recurrence (regurgitant volume as a continuous variable).

Multivariate logistic regression analysis was performed to assess the effect of preoperative tethering on the recurrence of MR. Forty demographic, clinical, and echocardiographic parameters were chosen on the basis of our previous experience. ${ }^{5}$ To enhance the accuracy of the model, the number of variables was reduced using variable clustering. Model fit for logistic regression analysis was assessed with the Hosmer-Lemeshow statistic and predictive accuracy was assessed using the concordance index c.

For presentation purposes, we first analyzed the main effect of preoperative tethering and then investigated the model adjusted for variables recognized as key factors of MR recurrence. ${ }^{5,7}$ Internal validation of the predictors generated by multivariate logistic regression analysis was performed using bootstrapping techniques, with 1000 cycles and generation of the odds ratios (ORs) and bias-corrected $95 \%$ confidence intervals (CIs).

Finally, to assess whether the predictive value of $\alpha^{\prime}$ was secondary to other factors such as abnormal LV function and geometry, we estimated the effect of $\alpha^{\prime}$ and $\beta^{\prime}$ in subgroups that included the systolic sphericity index (cutoff, 0.7), end-systolic volume (cutoff, $145 \mathrm{~mL}$ ), myocardial performance index (cutoff, 0.9), wall motion score index (cutoff, 1.5), and coaptation height (cutoff, $11 \mathrm{~mm}$ ). ${ }^{5,7,8}$ For the PML tethering angle, a cutoff of $45^{\circ}$ or greater was chosen. ${ }^{4}$ The effect of the AML tethering angle in each of the subgroups was estimated using logistic regression analysis and compared with $\beta^{\prime}$ of 45 or greater. Next, we tested for interactions between $\alpha^{\prime}$ and the subgroup variables using a multivariate general linear model.

The Statistical Package for Social Sciences, version 12.0 (SPSS, Chicago, Ill) and StatsDirect, version 2.5.7 (StatsDirect, Cheshire, UK) were used for these calculations.

\section{RESULTS}

\section{Recurrent MR}

At follow-up, 99 patients $(22.7 \%)$ showed recurrent MR. It developed in $39.4 \%$ of patients with severe $(n=39)$, $28.3 \%$ with moderate-severe $(n=28), 15.1 \%$ with moderate $(\mathrm{n}=15), 11.1 \%$ with mild $(\mathrm{n}=11)$, and $6.1 \%$ with normal/slight $(n=6)$ AML tethering. The tenting area was reduced preoperatively in groups 1 to $3\left(2.5 \mathrm{~cm}^{2}, 2.7 \mathrm{~cm}^{2}\right.$, and $2.7 \mathrm{~cm}^{2}$, respectively; $\left.P<.001\right)$ but did not change significantly in groups 4 and $5\left(3.8 \mathrm{~cm}^{2}\right.$ and $3.7 \mathrm{~cm}^{2}$, respectively; $P<.001$ vs groups $1-3)$. The coaptation length was less than $8 \mathrm{~mm}$ in all patients in groups 4 and 5 (3.9 $\mathrm{mm}$ and $3.6 \mathrm{~mm}$, respectively), and it was lower than in groups 1 to $3(8.4 \mathrm{~mm}, 8.4 \mathrm{~mm}$, and $8.6 \mathrm{~mm}$, respectively; $P<.001$ vs groups 1-3). At follow-up, 90 (90.9\%) of 99 patients with recurrent MR had asymmetric tethering with an eccentric jet without difference among the groups $(P=.87$ and $P=.9$, respectively).

\section{Associations With Outcome}

For all subjects, a strong correlation was found between the anterior mitral leaflet angle and recurrent MR ( $r=0.83, P<.001)$. This correlation was stronger in patients with severe AML tethering $(r=0.95, P<.001)$ than in those with moderate-severe $(r=0.56, P=.008)$, moderate $(r=0.55, P=.01)$, mild $(r=0.50, P=.03)$, or slight ( $r=0.31, P=.04$ ) AML tethering. In contrast, the correlation between the PML angle and MR recurrence was weak $(r=0.12, P=.05)$. Among the parameters of leaflet tethering, the correlation was significant between $\alpha^{\prime} / \beta^{\prime}(r=0.88, P<.001)$. Furthermore, a good correlation 
TABLE 1. Patient profiles $(n=435)$

\begin{tabular}{|c|c|c|c|c|c|c|}
\hline Variable & $\begin{array}{c}\text { Group 1 } \\
\text { (normal/slight, } \\
\left.\alpha^{\prime}<\mathbf{2 9 . 8}\right)^{\circ} \\
\end{array}$ & $\begin{array}{c}\text { Group 2 } \\
\left(\text { mild, } \alpha^{\prime} \geq 29.8^{\circ}\right. \\
\left.\text { but }<33.4^{\circ}\right) \\
\end{array}$ & $\begin{array}{c}\text { Group 3 } \\
\text { (moderate, } \boldsymbol{\alpha}^{\prime} \geq \mathbf{3 3 . 4 ^ { \circ }} \\
\text { but }<36.9^{\circ} \text { ) } \\
\end{array}$ & $\begin{array}{c}\text { Group 4 } \\
(\text { moderate-severe, } \\
\alpha^{\prime} \geq \mathbf{3 6 . 9}^{\circ} \text { but }<\mathbf{4 0 . 1}^{\circ} \text { ) } \\
\end{array}$ & $\begin{array}{c}\text { Group } 5 \\
\text { (severe, } \\
\alpha^{\prime}>\mathbf{4 0 . 1}^{\circ} \text { ) } \\
\end{array}$ & $\begin{array}{c}P \\
\text { value } \\
\end{array}$ \\
\hline Age (y) & $65.8 \pm 6.2$ & $66.1 \pm 7.4$ & $66.0 \pm 6.9$ & $66.5 \pm 6.7$ & $67.1 \pm 7.0$ & .8 \\
\hline Gender & & & & & & .007 \\
\hline Male & $51(58.6)$ & $52(59.7)$ & $50(57.5)$ & $52(59.7)$ & $54(62.0)$ & \\
\hline Female & $36(41.4)$ & $35(40.3)$ & $37(42.5)$ & $35(40.3)$ & $33(38.0)$ & \\
\hline NYHA class & $3[3-4]$ & $3[3-4]$ & $3[3-4]$ & $3[3-4]$ & $3[3-4]$ & $>.9$ \\
\hline CCS angina class & $2[1-3]$ & $2[1-3]$ & $2[1-3]$ & $2[1-3]$ & $2[1-3]$ & $>.9$ \\
\hline \multicolumn{7}{|l|}{ EuroScore } \\
\hline Additive & $8.0[6-9]$ & 8.2 [7-9] & $8.2[7-9]$ & $8.4[7-10]$ & $8.7[7-10]$ & .08 \\
\hline Logistic & $15.0[12-18]$ & 14.8 [12-18] & $14.9[12-18]$ & $15.2[12-18]$ & 15.5 [12-19] & .1 \\
\hline Hypertension & $30(36.3)$ & $32(36.7)$ & $39(44.8)$ & $44(39.0)$ & $40(45.9)$ & .006 \\
\hline \multicolumn{7}{|l|}{ Myocardial infarction } \\
\hline Inferior/posterior & $45(51.8)$ & $48(55.2)$ & $42(48.3)$ & $44(50.6)$ & $48(55.2)$ & \\
\hline Anterior/septal & $8(9.2)$ & $5(5.8)$ & $10(11.4)$ & $6(6.9$ & $4(4.6)$ & .53 \\
\hline Lateral & $6(6.9)$ & $5(5.8)$ & $8(9.2)$ & $7(8.0)$ & $4(4.6)$ & \\
\hline Combined & $28(32.1)$ & $29(33.2)$ & $27(31.1)$ & $30(34.5)$ & 31 (35.6) & \\
\hline \multicolumn{7}{|l|}{ Surgery } \\
\hline CPB time (min) & 111 [94-119] & 105 [95-120] & $109[98-115]$ & 110 [100-126] & 110 [100-130] & .09 \\
\hline CCL time (min) & 82 [60-98] & 85 [63-100] & 87 [64-99] & 91 [70-106] & 96 [70-108] & .06 \\
\hline \multicolumn{7}{|l|}{ Mitral ring } \\
\hline Carpentier classic* & $56(64.3)$ & $60(68.9)$ & $58(66.6)$ & $56(64.3)$ & $61(70.1)$ & .75 \\
\hline Physio & $31(35.7)$ & $27(31.1)$ & $29(33.4)$ & $29(35.7)$ & $26(29.9)$ & \\
\hline Ring size (mm) & $28[26-30]$ & $28[26-30]$ & $28[26-30]$ & $28[26-30]$ & $28[26-30]$ & $>.9$ \\
\hline \multicolumn{7}{|l|}{$\mathrm{CABG}$} \\
\hline Anastomoses/patient & $2[2-3]$ & $2[2-3]$ & $2[2-3]$ & $2[2-3]$ & $2[2-3]$ & $>.9$ \\
\hline Arterial graft/patient & $1[1-2]$ & $1[1-2]$ & $1[1-2]$ & $1[1-2]$ & $1[1-2]$ & $>.9$ \\
\hline \multicolumn{7}{|l|}{ Mitral regurgitation } \\
\hline MR (grade) & $3[3-4]$ & $3[3-4]$ & $3[3-4]$ & $3[3-4]$ & $3[3-4]$ & $>.9$ \\
\hline $\mathrm{ERO}\left(\mathrm{mm}^{2}\right)$ & $35 \pm 9$ & $36 \pm 10$ & $38 \pm 12$ & $38 \pm 12$ & $39 \pm 12$ & .5 \\
\hline $\mathrm{RF}(\%)$ & $45 \pm 12$ & $46 \pm 12$ & $47 \pm 13$ & $46 \pm 13$ & $47 \pm 12$ & .5 \\
\hline $\mathrm{RV}$ (mL/beat) & $55 \pm 13$ & $57 \pm 14$ & $58 \pm 15$ & $58 \pm 13$ & $59 \pm 15$ & .7 \\
\hline $\mathrm{TA}\left(\mathrm{cm}^{2}\right)$ & $3.2 \pm 1.0$ & $3.2 \pm 1.0$ & $3.4 \pm 1.1$ & $3.9 \pm 1.1 \dagger$ & $4.3 \pm 1.1 \dagger$ & $<.001$ \\
\hline $\mathrm{CL}(\mathrm{mm})$ & $3.4 \pm 0.2$ & $3.5 \pm 0.2$ & $3.5 \pm 0.2$ & $4.0 \pm 0.3$ & $3.9 \pm 0.3$ & .064 \\
\hline $\mathrm{d}(\mathrm{mm})$ & $35.1 \pm 6.7$ & $35.7 \pm 7.4$ & $35.9 \pm 6.8$ & $34.7 \pm 6.5$ & $37.9 \pm 6.8$ & .51 \\
\hline $\mathrm{h}(\mathrm{mm})$ & $10.4 \pm 3.3$ & $10.2 \pm 3.4$ & $10.9 \pm 3.5$ & $11.9 \pm 3.7 \dagger$ & $13.8 \pm 4.2 \dagger$ & .03 \\
\hline \multicolumn{7}{|l|}{ Mitral leaflet tethering } \\
\hline$\beta^{\prime}\left({ }^{\circ}\right)$ & $50 \pm 10$ & $54 \pm 12$ & $50 \pm 12$ & $50 \pm 12$ & $50 \pm 10$ & .79 \\
\hline$\alpha^{\prime} / \beta^{\prime}$ & $0.59 \pm 0.5$ & $0.59 \pm 0.5$ & $0.68 \pm 0.5$ & $0.78 \pm 0.5 \dagger$ & $0.80 \pm 0.8$ & .001 \\
\hline$\alpha_{\mathrm{ex}}^{\prime}\left({ }^{\circ}\right)$ & $35.9 \pm 4.6$ & $36.9 \pm 5.2$ & $33.1 \pm 4.5$ & $29.3 \pm 3.2 \dagger$ & $28.0 \pm 3.1 \dagger$ & .03 \\
\hline$\beta_{\mathrm{ex}}^{\prime}\left({ }^{\circ}\right)$ & $14.5 \pm 3.7$ & $14.0 \pm 4.0$ & $14.6 \pm 4.9$ & $13.9 \pm 4.0$ & $13.0 \pm 4.0$ & .36 \\
\hline \multicolumn{7}{|l|}{ LV remodeling } \\
\hline $\mathrm{ESD}(\mathrm{mm})$ & $46 \pm 5$ & $50 \pm 7$ & $46 \pm 6$ & $53 \pm 8 \dagger$ & $55 \pm 9 \dagger$ & $<.001$ \\
\hline $\mathrm{EDD}(\mathrm{mm})$ & $57 \pm 6$ & $59 \pm 8$ & $55 \pm 7$ & $65 \pm 7 \dagger$ & $67 \pm 9 \dagger$ & $<.001$ \\
\hline $\mathrm{ESV}(\mathrm{mL})$ & $107 \pm 20$ & $111 \pm 22$ & $110 \pm 23$ & $141 \pm 25 \dagger$ & $164 \pm 24 \dagger$ & $<.001$ \\
\hline $\mathrm{EDV}(\mathrm{mL})$ & $174 \pm 23$ & $166 \pm 23$ & $171 \pm 28$ & $190 \pm 29 \dagger$ & $201 \pm 26 \dagger$ & $<.001$ \\
\hline $\mathrm{SI}_{\mathrm{s}}$ & $0.55 \pm 0.1$ & $0.56 \pm 0.1$ & $0.55 \pm 0.1$ & $0.76 \pm 0.1 \dagger$ & $0.82 \pm 0.1 \dagger$ & $<.001$ \\
\hline $\mathrm{SI}_{\mathrm{D}}$ & $0.60 \pm 0.2$ & $0.62 \pm 0.1$ & $0.62 \pm 0.1$ & $0.80 \pm 0.1 \dagger$ & $0.88 \pm 0.1 \dagger$ & $<.001$ \\
\hline MPI & $0.52 \pm 0.1$ & $0.64 \pm 0.1$ & $0.66 \pm 0.1$ & $0.95 \pm 0.1 \dagger$ & $1.01 \pm 0.3 \dagger$ & $<.001$ \\
\hline \multicolumn{7}{|l|}{$\begin{array}{l}\text { Papillary muscle } \\
\text { displacement }\end{array}$} \\
\hline \multicolumn{7}{|l|}{ Posterior displacement } \\
\hline ALPM $(\mathrm{cm})$ & $2.4 \pm 0.3$ & $2.5 \pm 0.3$ & $2.6 \pm 0.3$ & $3.3 \pm 0.5 \dagger$ & $3.3 \pm 0.5 \dagger$ & $<.001$ \\
\hline PMPM $(\mathrm{cm})$ & $2.6 \pm 0.5$ & $2.5 \pm 0.5$ & $2.5 \pm 0.5$ & $2.5 \pm 0.5$ & $2.5 \pm 0.4$ & .87 \\
\hline
\end{tabular}




\begin{tabular}{|c|c|c|c|c|c|c|}
\hline Variable & 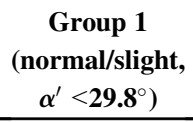 & $\begin{array}{c}\text { Group 2 } \\
\left(\text { mild, } \alpha^{\prime} \geq 29.8^{\circ}\right. \\
\text { but }<33.4^{\circ} \text { ) } \\
\end{array}$ & $\begin{array}{c}\text { Group 3 } \\
\left(\begin{array}{c}\text { moderate, } \alpha^{\prime} \geq 33.4^{\circ} \\
\left.\text { but }<36.9^{\circ}\right)\end{array}\right. \\
\end{array}$ & $\begin{array}{c}\text { Group 4 } \\
(\text { moderate-severe, } \\
\alpha^{\prime} \geq \mathbf{3 6 . 9}^{\circ} \text { but }<\mathbf{4 0 . 1}^{\circ} \text { ) }\end{array}$ & $\begin{array}{c}\text { Group } 5 \\
\text { (severe, } \\
\alpha^{\prime}>\mathbf{4 0 . 1}^{\circ} \text { ) } \\
\end{array}$ & $\begin{array}{c}P \\
\text { value } \\
\end{array}$ \\
\hline \multicolumn{7}{|l|}{ Lateral displacement } \\
\hline $\operatorname{ALPM}(\mathrm{cm})$ & $1.3 \pm 0.2$ & $1.2 \pm 0.3$ & $1.2 \pm 0.3$ & $1.5 \pm 0.4 \dagger$ & $1.6 \pm 0.4 \dagger$ & .004 \\
\hline PMPM (cm) & $2.0 \pm 0.4$ & $1.9 \pm 0.3$ & $1.9 \pm 0.3$ & $2.0 \pm 0.3$ & $2.0 \pm 0.4$ & .89 \\
\hline PM separation $(\mathrm{cm})$ & $3.3 \pm 0.4$ & $3.3 \pm 0.4$ & $3.4 \pm 0.4$ & $3.7 \pm 0.6$ & $3.6 \pm 0.6 \dagger$ & .01 \\
\hline \multicolumn{7}{|l|}{ WMSI } \\
\hline ALPM & $1.2 \pm 0.1$ & $1.3 \pm 0.2$ & $1.3 \pm 0.2$ & $1.5 \pm 0.4 \dagger$ & $1.5 \pm 0.4 \dagger$ & .001 \\
\hline PMPM & $2.0 \pm 0.3$ & $2.0 \pm 0.3$ & $2.0 \pm 0.3$ & $2.1 \pm 0.3$ & $2.0 \pm 0.3$ & .9 \\
\hline
\end{tabular}

Continuous variable presented as mean \pm standard deviation, discrete variables as percentages; non-normal variables as median [interquartile range]. $\alpha^{\prime}$, anterior mitral leaflet tethering angle; $\alpha_{e x}^{\prime}$ anterior mitral leaflet excursion angle; $A L P M$, anterolateral papillary muscle; $\beta^{\prime}$, posterior mitral leaflet tethering angle; $\beta^{\prime}{ }_{e x}$, posterior mitral leaflet excursion angle; $C A B G$, coronary artery bypass grafting; $C C L$, (aortic) cross-clamp; $C C S$, Canadian Cardiovascular Class; $C L$, coaptation length; $C P B$, cardiopulmonary bypass; $d$, coaptation distance; $E D D$, end-diastolic diameter; $E D V$, end-diastolic volume; $E R O$, effective regurgitant orifice ( $\left.\mathrm{mm}^{2}\right) ; E S D$, end-systolic diameter; $E S V$, end-systolic volume; $h$, coaptation height; $L V$, left ventricular; $M P I$, myocardial performance index; $M R$, mitral regurgitation; NYHA, New York Heart Association; $P M P M$, posteromedial papillary muscle; $P M s$, papillary muscles; $R F$, regurgitant fraction; $R V$, regurgitant volume; $S I D$, diastolic sphericity index; $S I S$, systolic sphericity index; $T A$, tenting area; $W M S I$, wall motion score index. *Significance at post hoc test vs groups $1-3$. †Edwards LifeSciences, Irvine, CA.

was found between $\alpha^{\prime}{ }_{\text {ex }}(r=0.66, P=.02)$ and recurrent MR, although no significant correlation was found between $\beta_{\text {ex }}^{\prime}$ and MR recurrence $(r=0.09, P=.43)$.

On multivariate regression analysis corrected by other echocardiographic risk factors, AML tethering that was moderate-severe or greater (OR, 3.6; 95\% CI, 3.0-4.0; $P<.001)$, a symmetric pattern (OR, 3.4; 95\% CI, 2.85.0; $P<.001)$, and anterior leaflet excursion angle less than $35^{\circ}(\mathrm{OR}, 2.0 ; 95 \% \mathrm{CI}, 1.5-2.6 ; P=.007)$ were strong predictors of recurrent regurgitation (Hosmer-Lemeshow test $=0.7$, c-index $=0.7$ ). Compared with patients with posterior leaflet tethering of $45^{\circ}$ or greater (adjusted OR, 1.07; 95\% CI, 0.09-1.2; $P=.073$ ), those with moderate-severe AML tethering (adjusted OR, 1.9; 95\% CI, 1.5-2.5; $P=$ $.044)$ had 1.7 times greater odds of MR recurrence (Figure 1, A). The increase in risk associated with severe AML tethering was greater than 3.7-fold (OR, 4.0; 95\% CI, 3.5-4.6; $P<.001$ ).

The model proved to be reliable (Hosmer-Lemeshow test, $P=.7$ ) and accurate (c-index $=0.8$ ).

When we allowed for an interaction between the AML tethering angle and other risk factors (Figure 1, $B$ and $C$ ), the predictive value of $\alpha^{\prime}$ was significant across a wide spectrum of patients, and the ORs were always greater compared with those for PML $\geq 45^{\circ}$. This effect also occurred in lowrisk subgroups and was equivalent or generally attenuated in higher risk patients. No significant interaction was found between the $\alpha^{\prime}$ and any of the covariates (all, $P \geq .05$ ).

\section{DISCUSSION}

The present multicenter experience adds to a growing body of data documenting recurrent ischemic MR after undersized mitral annuloplasty and coronary artery bypass grafting. The present study builds on these findings by examining the real effect of preoperative AML tethering on the recurrence of MR after annuloplasty. Clinical data, as well additional treatment options, offered for patients with the discovery of recurrent MR have not been included.

In a previous experience, ${ }^{5}$ we have shown that that a preoperative AML tethering angle of $39.5^{\circ}$ or greater had a very high sensitivity and specificity to predict recurrent MR after surgery, although the PML tethering was not significant. Nonetheless, the altered leaflet geometry and recurrent MR could both be the result of abnormal LV function and geometry, which might be primary predictors.

In the present, large, multicenter study, the predictive value of AML tethering was confirmed. Compared with patients with a posterior leaflet tethering of $45^{\circ}$ or greater, those with moderate-severe AML tethering had 1.7 times greater odds of MR recurrence. The increase in risk associated with severe AML tethering was $>3.7$-fold. Furthermore, when we allowed for an interaction between $\alpha^{\prime}$ and the other risk factors, severe AML tethering was associated with increased MR recurrence in patients with systolic sphericity index of less than 0.7 , end-systolic volume of less than $145 \mathrm{~mL} / \mathrm{m}^{2}$, myocardial performance index less than 0.9 , wall motion score index less than 1.5 , and coaptation height less than $11 \mathrm{~mm}^{8}$ This effect was equivalent or generally attenuated in higher risk patients with a significant effect of severe AML tethering also on the outcomes in low-risk subgroups. Also, we failed to find any interaction between $\alpha^{\prime}$ and other variables, and this demonstrates that AML tethering is a primary predictor of MR, and its effect is not secondary to LV function and geometry.

Ciarka and colleagues ${ }^{9}$ demonstrated that tethering of both leaflets is associated with recurrent MR. Nonetheless, the inclusion in their study of 40 patients $(37 \%)$ receiving a cardiac support device made it difficult to compare their results with those from our study. Furthermore, our findings 


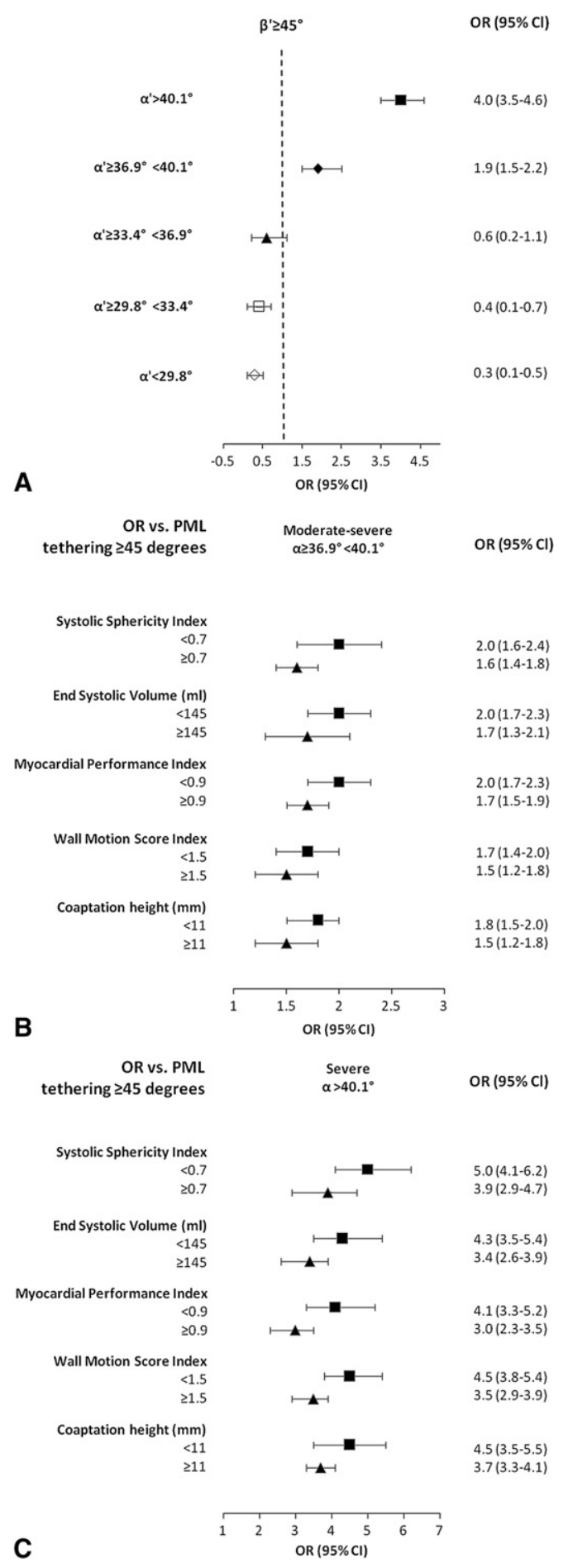

FIGURE 1. A, Odds ratios (ORs) and $95 \%$ confidence intervals (CIs) of posterior mitral leaflet tethering angle $\beta^{\prime}$ and different quintiles of anterior mitral leaflet tethering angle $\alpha^{\prime}$ in predicting mitral regurgitation $(M R)$ recurrence after reductive annuloplasty. B, Subgroup analysis: OR and $95 \%$ $\mathrm{CI}$ of moderate-severe anterior mitral leaflet $(A M L)$ tethering versus posterior mitral leaflet $(P M L)$ tethering angle $\beta^{\prime} 45^{\circ}$ or greater in different subgroups of patients. C, Subgroup analysis: OR and $95 \%$ CI of severe AML tethering versus PML tethering angle $\beta^{\prime}$ of $45^{\circ}$ or greater in different subgroups of patients. are in contrast with those from Kuwahara and colleagues ${ }^{3}$ and Magne and colleagues, ${ }^{4}$ who showed that the PML tethering angle was a primary predictor of MR. Different methods in calculating the tethering angle might explain these conflicting results. However, this topic deserves additional investigation to establish the true effect of both leaflets tethering on the recurrence of MR.

\section{Clinical Implications}

The clinical implications of the present study are important, because they suggest that patients with MR recurrence after UMRA for ischemic MR can prospectively be identified on the basis of preoperative echocardiographic findings. Hence, our results show that the procedure is more likely to fail in patients with an AML tethering angle of moderate-severe or greater. In such patients, concomitant or alternative surgery addressing the leaflet tethering should be considered. We recently started to use, in these patients, the RING plus STRING technique ${ }^{10}$ which combines the annuloplasty with repositioning of the posterior papillary muscle toward the midseptal fibrous annulus (or saddle horn) in the loaded, beating heart. Apart from eliminating the need for aggressive annular undersizing, this technique should prevent posterior continued remodeling, which has been demonstrated to occur after UMRA.${ }^{5,7}$ Furthermore, mitral valve replacement might play a role in these patients with extreme or unfavorable AML tethering. However, long-term data are necessary to confirm the optimal management in these circumstances.

\section{Study Limitations}

The main limitations of the present study were its retrospective nature and the lack of information on myocardial viability. In the present experience, we used only 2 rings, which were not at all identical. Thus, although we undersized both rings by 2 sizes, we might have been less restrictive with the physio ring than with the classic ring. However, in our previous experience, ${ }^{7}$ neither the ring type nor the ring size was predictive of recurrent MR. How LV remodeling and recurrent MR after UMRA are influenced by the viability of the revascularized myocardium is object of an ongoing study. Furthermore, the evaluations were based on 2-dimensional echocardiographic measurements that rely on an image plane and geometric assumptions, which might not be valid when myocardial infarction affects the ventricular shape. Threedimensional echocardiographic reconstruction of the endocardial surface would eliminate the need for these assumptions.

\section{CONCLUSIONS}

Preoperative AML tethering is a powerful predictor of MR recurrence after UMRA independently of LV 
geometry and LV dilation. Assessment of leaflet tethering by 2-dimensional echocardiography should be incorporated into the clinical risk assessment and prediction models.

We gratefully acknowledge Dr Orlando Parise for statistical analysis. We thank Mr. James Douglas for the English revision of our report.

\section{References}

1. ten Brinke EA, Klautz RJ, Tulner SA, Verwey HF, Bax JJ, Delgado V, et al. Clinical and functional effects of restrictive mitral annuloplasty at midterm follow-up in heart failure patients. Ann Thorac Surg. 2010;90:1913-20.

2. Bouma W, van der Horst IC, Wijdh-den Hamer IJ, Erasmus ME, Zijlstra F, Mariani MA, et al. Chronic ischaemic mitral regurgitation: current treatment results and new mechanism-based surgical approaches. Eur J Cardiothorac Surg. 2010;37:170-85.

3. Kuwahara E, Otsuji Y, Iguro Y, Ueno T, Zhu F, Mizukami N, et al. Mechanism of recurrent/persistent ischemic/functional mitral regurgitation in the chronic phase after surgical annuloplasty: importance of augmented posterior leaflet tethering. Circulation. 2006;114(Suppl.):1529-34.
4. Magne J, Pibarot P, Dagenais F, Hachicha Z, Dumesnil JG, Senechal M. Preoperative posterior leaflet angle accurately predicts outcome after restrictive mitral valve annuloplasty for ischemic mitral regurgitation. Circulation. 2007;115:782-91

5. Gelsomino S, Lorusso R, Caciolli S, Capecchi I, Rostagno C, Chioccioli M, et al Insights on left ventricular and valvular mechanisms of recurrent ischemic mitral regurgitation after restrictive annuloplasty and coronary artery bypass grafting. $J$ Thorac Cardiovasc Surg. 2008;136:507-18.

6. Cohen J. A coefficient of agreement for nominal scales. Educ Psychol Meas. 1960;20:37-46.

7. Gelsomino S, Lorusso R, De Cicco G, Capecchi I, Rostagno C, Caciolli S, et al. Five-year echocardiographic results of combined undersized mitral ring annuloplasty and coronary artery bypass grafting for chronic ischaemic mitral regurgitation. Eur Heart J. 2008;29:231-40.

8. Calafiore AM, Di Mauro M, Gallina S, Di Giammarco G, Iacò AL, Teodori G, et al. Mitral valve surgery for chronic ischemic mitral regurgitation. Ann Thorac Surg. 2004;77:1989-97.

9. Ciarka A, Braun J, Delgado V, Versteegh M, Boersma E, Klautz R, et al. Predictors of mitral regurgitation recurrence in patients with heart failure undergoing mitral valve annuloplasty. Am J Cardiol. 2010;106:395-401.

10. Langer F, Schäfers HJ. RING plus STRING: papillary muscle repositioning as an adjunctive repair technique for ischemic mitral regurgitation. J Thorac Cardiovasc Surg. 2007; 133:247-9. 